\title{
Cotas: por que
}

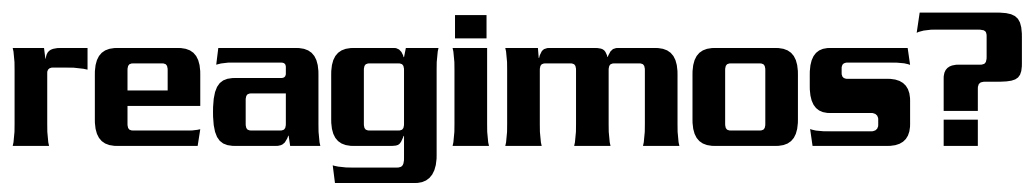

RITA LAURA

SEGATO é professora

do Departamento

de Antropologia da

Universidade de Brasilia.

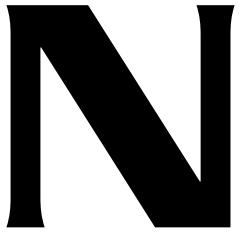

o Brasil, aqueles que defendemos a instauração de um regime de cotas ficamos muitas vezes perplexos pelo caráter excessivamente veemente, apaixonado e, por momentos, até virulento de algumas reações. Tentarei, na primeira parte do meu argumento, apontar algumas das razões que colocam obstáculos à compreensão da proposta para estudantes negros e que podem explicar a ansiedade com que alguns reagem a ela. Em seguida, passo a listar as formas de eficácia que a introdução de um sistema de cotas teria para transformar positivamente o sistema educativo e a sociedade que ele reproduz. 
gete RAZúEg PARA A REAÇÃo

\section{DU PÚBLICO BRAGILEIRO AO}

\section{Programa de cotag: as áreas}

\section{DE DESCONHECIMIENTO E OS}

\section{PONTOS NEVRÁlgICOS DAS}

\section{RELAÇŨES RACIAIS NO BRAGIL}

1. Falta de reflexãa e informaçãa:

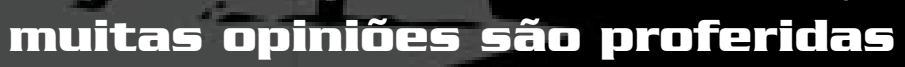
na ignorância das fatas que sustentam a debate

Em primeiro lugar, a falta de informaçãa. Nãa há, no Brasil, uma prática de discussãán ampla e assídua do público sobre igualdade de àcesso a direitos e recursos em geral e em particular sobre racismo. Isso faz com que a maioria das pessoas, incluinda a público universitário e mesmo muitos profissionais do Direito, não se encontre suficientemente informada sobre a evolução e a estado deste já longo debate sobre açães afirmativas na cena internacional. Nem mesmo a vocabulário internacionalmente aceito sobre o tema é devidamente utilizado pela pública.

Esse desconhecimento alcança inclusive os setores da sociedade que dispãem de maior acesso à educaçãa e aos meios de informação. Quando, no dia 28 de fevereiro de 2002, 0 presidente da Federação de Indústrias de 5ão Paulo reagia se declárando "abalado" ao ler nos jornais as primeiras notícias dos resultados da pesquiśa do Ipea sobre índices de exclusãa dos negros, sua surpresa manifesta revelou que algo tinha falhado nos modelos de representação da sociedade brasileira elahorados até então pelas ciências sociais. 
L.t 20 S

$12-2$

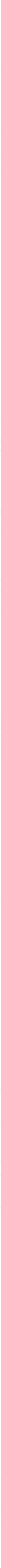
s.

$e^{2} e^{2}$ .... 


\section{As diversas formas do racismo} no Brasil

Em segundo lugar, a falta de esclarecimento, que faz com que, em muitas ocasiões e cenários dos mais variados, às vezes discriminemos, excluamos e até maltratemos por motivos raciais, sem ter qualquer grau de percepção de que estamos incorrendo num ato de racismo. Se existem pelo menos quatro tipos de ações discriminatórias de cunho racista, as mais conscientes e deliberadas não são as mais frequientes entre nós. Isso leva a que muitos não tenhamos consciência da necessidade de criar mecanismos de correção para contrapor à tendência espontânea de beneficiar o branco em todos os âmbitos da vida social brasileira.

Os quatro tipos de racismo mais comuns podem ser definidos como segue:

- Um racismo prático: automático, irrefletido, naturalizado, culturalmente estabelecido e que não chega a ser reconhecido ou explicitado como atribuição de valor ou ideologia. Opõe-se aos racismos fundamentados numa consciência discursiva. O professor de escola que simplesmente não acredita que o aluno negro possa ser inteligente, que não o ouve quando fala nem o percebe na sala de aula. $O$ porteiro do edifício de classe média que não pode conceber que um dos proprietários seja negro. A família que aposta sem duvidar nas virtudes do seu membro de pele mais clara. Esse tipo de atitude aparentemente irrefletida é a que resulta na reprodução do processo contínuo de exclusão de grande porte que chamamos de "racismo estrutural" e "racismo institucional", e que resiste à identificação de uma autoria ou à alocação de responsabilidade.

- Um racismo axiológico: se expressa através de um conjunto de valores e crenças que atribui predicados negativos ou positivos em função da cor da pessoa. $O$ professor universitário que, em aula, proclama que "todos nós sabemos que os negros são inferiores intelectualmente ao branco, mas isso não é razão para que os tratemos mal" - exemplo que tomei do relato de um estudante do curso de Letras desta universidade.

- Um racismo emotivo: expressa-se manifestando rancor, ressentimento ou medo em relação a pessoas de outra raça. Alguém que, em um elevador, assusta-se por estar em companhia de uma pessoa negra, ou que adverte os filhos de que não façam amizade com colegas dessa cor.

- Um racismo político e, em alguns países, até partidário: grupos políticos que advogam o antagonismo aberto contra setores da população racialmente marcados. O Partido Nacional Australiano ou a Ku Klux Klan norte-americana são exemplos. Esta última variante é praticamente desconhecida no Brasil, à exceção de pequenos grupos neonazistas existentes em alguns centros urbanos de São Paulo, Rio de Janeiro e Rio Grande do Sul.

O primeiro desses quatro tipos é o mais freqüiente no Brasil. Curiosamente, apesar de se apresentar como a mais inocente das formas de discriminação racial, está longe de ser a mais inócua. Muito pelo contrário, é a que mais vítimas faz no convívio da vida escolar e aquela da qual é mais difícil defender-se, pois opera sem nomear. A ação silenciosa da discriminação automática torna o racismo uma prática estabelecida, costumeira, mas dificilmente detectável. Somente do outro lado da linha, no pólo distante e macroscópico das estatísticas, torna-se visível o resultado social desses incontáveis gestos microscópicos e rotineiros.

Esse racismo considerado ingênuo, porém letal para os negros, é o racismo diário e difuso do cidadão - qualquer um de nós, professores - cujo crime é, pelo menos aparentemente, estar desavisado sobre o assunto. É esse racismo dos que nos consideramos bem-intencionados que constitui o gargalo e escoadouro dos alunos negros, impedindo-os de avançar no sistema educativo, derrubando-os no caminho sem que nem sequer possam apontar aquilo que os prejudica. Eé especialmente esse tipo de discriminação e seus efeitos nas escolas de todos os graus que as cotas vêm denunciar e corrigir. Sua ação é silenciosa, mas suas 
conseqüências falam alto nos números que as pesquisas recolhem, e podem ser constatadas na ausência de pessoas negras em profissões de prestígio e nos espaços de decisão.

\section{Racismo: zona de insensibilidade}

\section{da cultura brasileira}

Em terceiro lugar, uma razão cultural: o que se pode chamar de "o ponto cego da sensibilidade brasileira", já que, se consideramos que cada época e cada cultura tiveram uma área específica de insensibilidade e uma cegueira própria, não tenho dúvidas em afirmar que a nossa é a dos males do racismo com sua sequiela de sofrimentos. $\mathrm{O}$ padecimento moral e a insegurança das pessoas negras na nossa sociedade são inaudíveis, não encontram meios expressivos para se manifestar e não encontram registro nem no discurso midiático nem no acadêmico. Tanto os teóricos das ciências sociais quanto o senso comum o descrevem como parte de uma tradição, prática habitual, estilo de convivência, traço idiossincrático e até pitoresco da civilização brasileira. Esse sofrimento, que tem como causa pura e exclusivamente a cor da pele, é particularmente grande precisamente onde menos poderia ser admitido: nos espaços institucionais da esfera pública, dos quais a universidade é uma instância crucial.

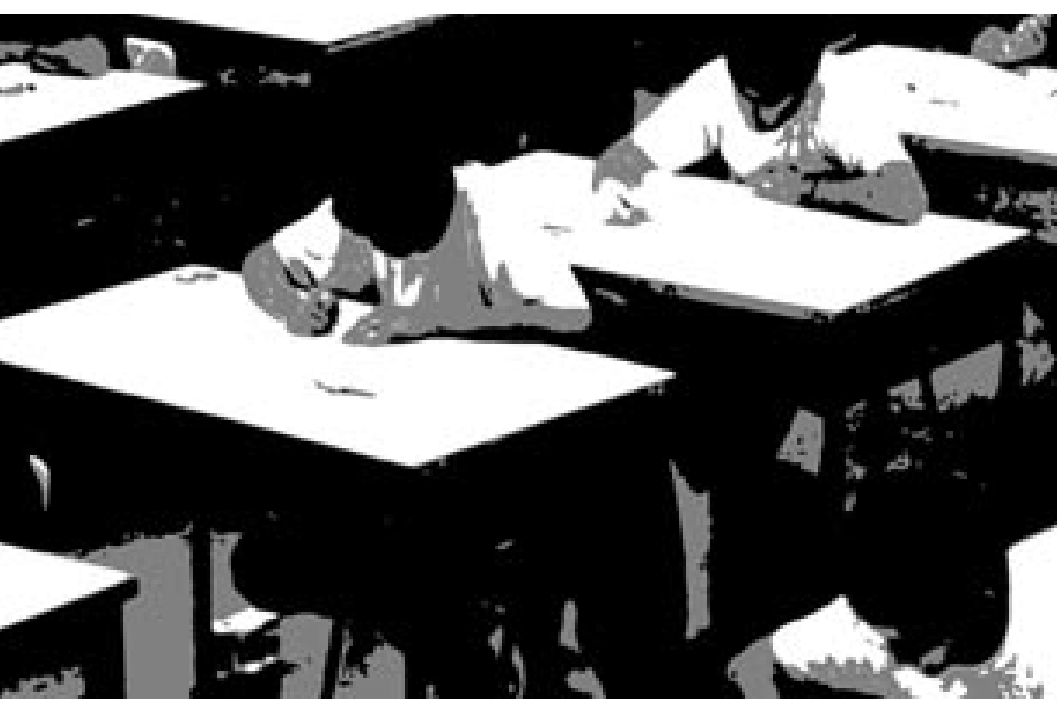

4. Asfamílias brasileiras "brancas",

à exceção daquelas formadas

exclusivamente por imigrantes

e seus descendentes não

miscigenados, lutaram por

\section{diluir e esquecer sua parcela de ancestralidade negra}

Em quarto lugar, uma razão de memória histórica como segredo guardado em família: por razões demográficas inescapáveis, a classe média "branca” brasileira de hoje produziu sua cor e o prestígio a ela associado por meio de um esforço constante de branqueamento, de mecanismos de controle severos sobre seus membros e de trabalho de esquecimento sistemático de seus componentes ancestrais não-brancos. A fala sobre cotas parece trazer como subtexto a afirmação de que esse esforço mancomunado da sociedade e sustentado até hoje por esquecer o escravo dentro de si, por apagar o traço do seu sangue, foi um esforço inútil. Ao introduzir o tema das cotas, passamos a mensagem de que nossas famílias se esforçaram, reprimiram e expurgaram em vão laços e memórias ao longo de gerações. Mais ainda: que o que elas conseguiram quando finalmente se alojaram no nicho prestigioso da brancura pode vir agora a se perder com a simples votação de um Conselho Universitário ou a assinatura de um decreto. Uma pergunta velada que se ouve por trás da ansiedade apenas dissimulada de muitas audiências diz respeito ao que entendemos como um retrocesso histórico no longo esforço por adquirir uma aparência condizente com a vocação moderna, ocidental, do Brasil: vamos agora auto-infringir-nos um recuo? Vamos ceder espaço, valorizar aquilo que por tanto tempo tentamos erradicar? Percebemos, então, que as nossas certezas assentavam-se num equívoco histórico e ético 
amplamente compartilhado e que o retrato do ancestral negro guardado na gaveta ou alterado pelo retoque de um fotógrafo de outros tempos nos torna para sempre parentes daqueles que hoje tentamos evitar, tanto nas nossas universidades como no seio das nossas famílias.

A verdade é que a maioria das nossas famílias agiram assim e alguns de nós ainda operamos com essas concepções. A demografia histórica do Brasil o prova de forma irrefutável. Se, apesar do forte racismo de todas as épocas, a miscigenação foi uma prática relativamente habitual do passado, inevitável porque a classe branca não era suficientemente numerosa para garantir sua própria reprodução biológica, econômica e cultural, hoje, quando essa classe média "branca" é já ampla, a antiga prática da miscigenação que produzira a cor do Brasil "incluído" dos nossos dias tornou-se estatisticamente irrelevante, para não dizer inexistente. Um processo de segregação crescente passou a tomar seu lugar e se instalou entre nós. A assim chamada "civilização brasileira" dos seguidores das teses de Gilberto Freyre precisa ser, finalmente, abordada numa perspectiva temporal, levando em consideração suas transformações históricas. Quando muito, trata-se de uma tese histórica, pois, se alguma vez foi verdadeira pelo menos para alguns, hoje ela não descreve os padrões de sociabilidade e de escolhas maritais do Brasil contemporâneo, onde os espaços de convivência inter-racial diminuíram dramaticamente ${ }^{1}$.

No Brasil dos nossos dias, mostra-nos o IBGE - à diferença do Brasil lendário da miscigenação que produziu a classe que hoje estuda e ensina nas universidades -, branco casa com branco, e pretos e pardos se unem e procriam entre si, sendo essa a tendência claramente dominante e amplamente estabelecida. O que significa isso? Pois significa que não são as cotas o fator que viria a "americanizar" o Brasil, como muitos sugerem, mas que o Brasil já se encontra em pleno processo de segregação e guetificação, ou seja, já se encontra “americanizado". Os contingentes raciais, portanto, perderam sua porosidade anterior;

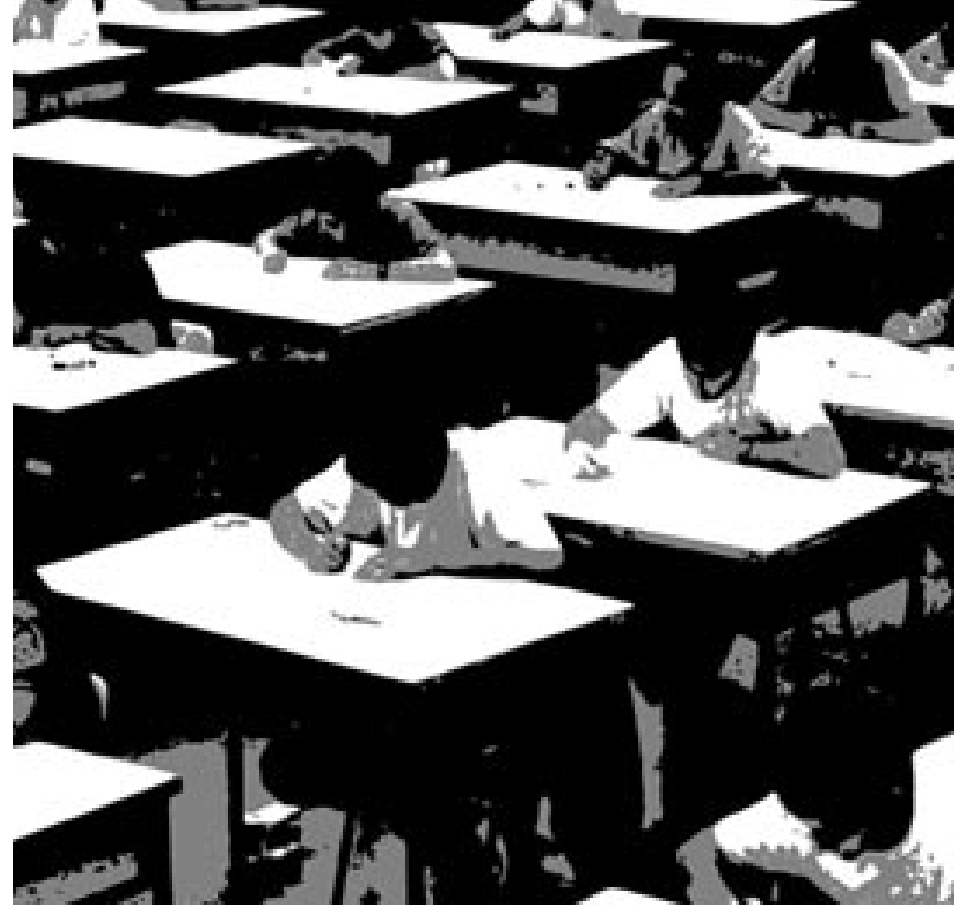

o território da brancura e as benesses que dispensa passam a ser, a cada dia, mais bem resguardados.

\section{0 sujeito da elite pós-escravocrata}

\section{se constitui numa paisagem de desigualdade e exclusão}

Em quinto lugar, uma razão psicológica, ancorada no padrão de formação da subjetividade de muitos brasileiros. A exclusão, entre nós, é uma estrutura profunda de ordem psíquica, cognitiva, ontológica e não meramente socioeconômica. Originária do sistema de exploração escravocrata, logo permaneceu enquistada na ideologia e reproduzida pela cultura do povo brasileiro. As relações sociais próprias da escravidão constituíram-se em matriz de convivência no Brasil, transformaram-se em "costume", numa forma de normalidade. Na sociedade brasileira pós-escravocrata, a suspensão da ordem jurídica que garantia a exclusão na lei foi substituída por uma caução ideológica, o racismo, que passou a ser a norma não-jurídica a garantir a permanência da exclusão das pessoas negras.

Portanto, é importante perceber que os excluídos não são produtivos somente no que diz respeito à extração de trabalho mal pago, eles também são produtivos na reprodução da subjetividade das classes domi-
"As uniões coniugais são carac terizadas pela predominância de endogamia racial. Embora - PNAD de 1999 mostre que aproximadamente $40 \%$ da população brasileira seja classificada como 'parda' apenas $22 \%$ das uniões brasileiras se dão entre pessoas de raças diferentes... Entre termos relativos, no entanto, a miscigenação, quando ocorre é mais comum entre pessoas que não são brancas, como os casais compostos por pardos e negros... A análise do perfil racial dos casais e das taxas de miscigenação das mutheres permite concluir que, se mantida a situação atual, o tamanho futuro da segunda maior egoria racial do país, a dos pardos, está, em sua maio parte, relacionada à própria reprodução da população de pardos, unidos a outros pardos, e não à mescla de brancos e negros, por exemplo, uma vez que esta última ocorre com pouca freqüência... Nas família monoparentais... os filhos são da mesma raça da mãe ou pa com quem vivem em cerca de $89 \%$ dos casos, independente da raça ou do sexo da mãe ou pai com quem vivem" IMarcelo Medeiros, 2002). Ver também análise dos dados sobre casamento inter-racial em Valle Silva (1992), que mostra a mesma tendência endogâmica. 


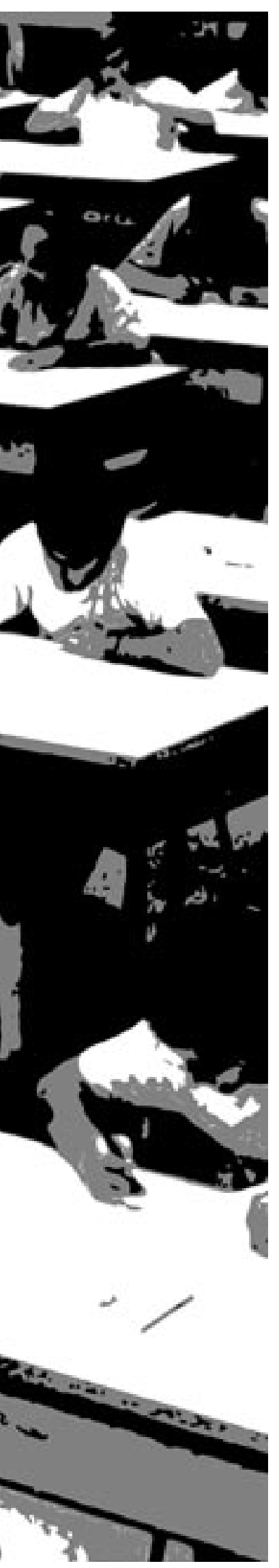

nantes. Os mecanismos de expurgo voltados para o próprio interior da sociedade nacional e vitimando particularmente os negros são cruciais para a reprodução do modo de sere a autopercepção das elites, incluindo a nós mesmos, a elite do saber. Os que excluem e os excluídos não formamos continentes apartados sem conexão. Muito pelo contrário, fazemos parte de uma economia única que diz respeito tanto à ordem material como à ordem psíquica da sociedade nacional. $\mathrm{O}$ expurgo de um outro racialmente marcado como inferior é o gesto no qual se assenta e do qual depende a identidade mesma do sujeito pós-escravista branco. Esse gesto reproduz, nas profundezas do psiquismo historicamente formado, a subjetividade da elite, que afirma o ser como ser-mais frente ao menos-ser dos excluídos, necessitando destes. Nessa economia canibalística, alterar a relação desigual das partes ameaça não somente a posição mas também a identidade mesma do sujeito de elite, ao tocar sua relação hierárquica de mais-ser em relação a outros que são-menos, geralmente marcados racialmente.

A universidade, pelo seu prestígio singular entre todas as instituições, é o centro de gravidade dessa estrutura histórica, a usina onde reproduzimos, representamos e justificamos os seus fluxos.

\section{A autoridade do professor}

\section{fundamenta-se no suposto da}

\section{lisura incontestável dos processos}

\section{de seleção que transpôs ao longo da sua carreira acadêmica}

Em sexto lugar, um dilema de legitimidade. Nós, professores, tememos que as cotas coloquem em questão os processos de aferição de mérito pelos quais atravessamos para chegar a ocupar as posições que hoje ocupamos. Com isso, as cotas pareceriam apontar, indiretamente, para um grau de ilegitimidade desses métodos, comprome- tendo a sua autoridade e a da instituição acadêmica. Reiteramos, nas nossas falas, insistentemente, a qualidade, a nobreza, a legitimidade dessa instituição, tentando deixar fora de questão qualquer crítica aos princípios de escolha e afunilamento que se encontram na base e fundamentam todas as práticas da vida universitária. Essa obstinação na defesa do cânone acadêmico mostra, acredito, entre outras, a insegurança endêmica que assola a produção e a transferência de conhecimento nos países periféricos, dependentes tecnologicamente. Nós professores sentimos que necessitamos exaltar com veemência o sistema que nos conferiu o prestígio do qual atualmente gozamos, e esquecemos que todo sistema de regras pode e deve ser aperfeiçoado continuamente. Somente o esforço pelo aprimoramento dos métodos e critérios de seleção atesta a nossa legitimidade comoeducadores preocupados para que as condições educativas e sociais das novas gerações sejam melhores que as do nosso tempo.

\section{0 comprometimento histórico}

\section{das ciências sociais na construcão} da imagem hegemônica da nação
brasileira como caso de relações

\section{raciais bem-sucedidas}

Finalmente, existe um entrave específico para o acolhimento da medida de cotas nos departamentos de ciências sociais, e especialmente nos de antropologia. Não posso me estender na análise dessa questão aqui, mas basta dizer que a antropologia brasileira teve como tarefa histórica ao seu cargo a produção de uma narrativa forte da nação que foi constelando em torno de si setores da direita e da esquerda do espectro político em torno de uma retórica nacionalista. O englobamento do negro numa posição subalterna, mas concordante, foi o tema central dessa retórica. Representar a nação significava, inevitavelmente, para o trabalho 
ideológico dessa antropologia, representá-la como uma sociedade fortemente estratificada no econômicoe no social, mas "cordial"e harmônica no cultural (o carnaval e futebol de um Roberto DaMatta, responsável pelo aggiornamento e adaptação à linguagem das ciências sociais do estilo ensaístico de Gilberto Freyre). Daí a curiosa e persistente importação até o presente de um autor como Louis Dumont, denunciado na Índia e praticamente esquecido nos grandes centros acadêmicos, mas onipresente nas aulas e nas teses brasileiras. Pois seu modelo mune o projeto ideológico da antropologia brasileira com categorias úteis na formulação da idéia de um escravo feliz, de um subalterno satisfeito, por força da cultura. Razões “civilizatórias” fazem calar a queixa dos que sofrem. O fato de que gerações de antropólogos somaram forças nessa tarefa de persuasão ideológica torna difícil abrir as portas a uma discussão que implicaria inevitavelmente uma mudança radical de paradigma e, com isso, uma circulação dos grupos que detêm o poder disciplinar.

\section{A EFICÁCIA DAS COTAS PARA} NEGROS NA UNIVERSIDADE: ANÁLISE DAS FORMAS DE IMPACTO NA ACADEMIA E NA SOCIEDADE EM GERAL

Não é possível pensar as cotas simplesmente como uma tentativa de alterar o perfil de injustiça social que prejudica os índices brasileiros ou como um mecanismo de desenvolvimento socioeconômico através de educação ampliada de setores menos favorecidos da população. Quem compreende as cotas dessa maneira estará reduzindo o fenômeno e deixará de perceber a proliferação de conseqüências e a disseminação do seu impacto numa variedade de dimensões da vida social. Nesta seção, analiso os possíveis benefícios de um pro- grama de cotas na universidade. Chamarei esses impactos de formas particulares de eficácia e identifico dez tipos.

\section{Eficácia reparadora}

Instaura, no espaço acadêmico, um mecanismo eficiente para ressarcir, pelo menos em parte, as perdas infringidas na nação brasileira ao componente negro da sua população. O processo de reparação histórica é amplamente discutido no momento, e a oferta educativa é certamente uma das suas instâncias.

As cotas acusam, com sua implantação, a existência do racismo, e o combatem de forma ativa. Esse tipo de intervenção é conhecido como "discriminação positiva”. A discriminação positiva constitui o fundamento das assim chamadas "ações afirmativas". As cotas são um tipo de ação afirmativa. Anoção de "reparação", ou seja, o ressarcimento por atos lesivos cometidos contra um povo assim como a noção de “compensação" pelas perdas ocasionadas são os conceitos que orientam e conferem sentido à implementação da medida.

Uma definição standard desses conceitos encontra-se no guia oficial dos Direitos Humanos publicado pela Unesco e seus verbetes foram extraídos dos textos dos Instrumentos Internacionais aprovados pelas Nações Unidas para a proteção e promoção dos Direitos Humanos:

“Questões vinculadas à prevenção e eliminação da discriminação são tratadas permanentemente pela Assembléia Geral das Nações Unidas, pelo Conselho Econômico e Social (Ecosoc), pela Comissão sobre Direitos Humanos e pela Subcomissão sobre Prevenção da Discriminação e Proteção das Minorias (agora Subcomissão para a Promoção e Proteção dos Direitos Humanos). Alcançar a igualdade não somente de jure mas também de fato demanda em alguns casos que seja implementada uma ação afirmativa pelos Estados para diminuir ou eliminar condições que causam a discriminação de indivíduos ou grupos.
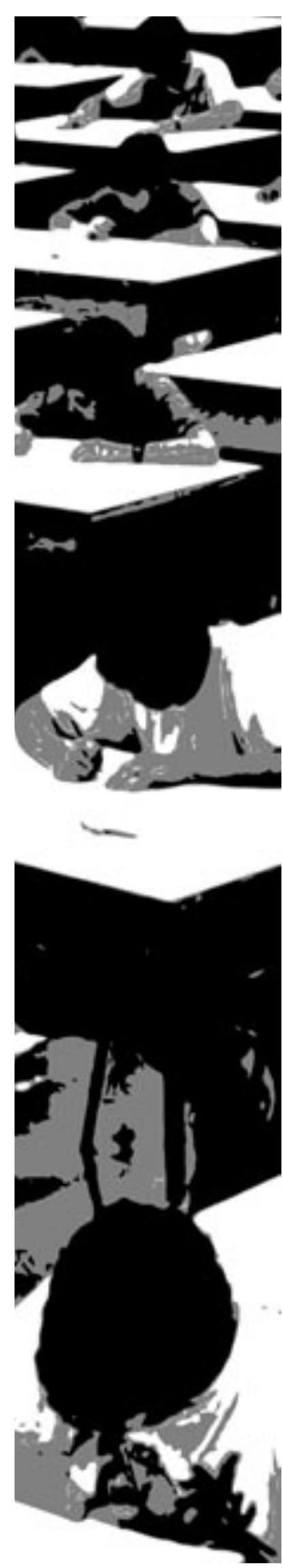
Discriminação inversa pode também existir e se chama 'discriminação positiva'. Este termo pode ser entendido como 'selecionar pessoas para méritos ou empregos na base de seu pertencimento a grupos oprimidos, inclusive se o membro de um grupo mais privilegiado se encontra mais bem qualificado', já que, é mister mencionar, o gozo de direitos humanos e liberdades fundamentais em igualdade de condições não significa tratamento idêntico em todas as instâncias" (Symonides \&Volodin, 2001, p. 162).

\section{Eficácia corretiva}

Redireciona o futuro de uma sociedade cuja história acumula um passivo monstruoso em relação à população negra. Corrige o rumo dessa história e estimula a confiança (hoje profundamente abalada pela memória histórica) dessa população nas instituições e no Estado brasileiro.

\section{Eficácia educativa imediata}

Garante o acesso à educação superior a representantes da população negra em função do seu mérito, medido de forma eqüitativa ao levar em consideração as desvantagens do estudante negro em todos os níveis do sistema educativo.

Nesse sentido, trata-se de uma medida de cunho emergencial. Portanto, não vem para substituir outras de longo prazo que propõem transformações mais profundas como a melhora e a universalização do ensino público e até as cotas para estudantes pobres ou formados na escola pública. Éuma medida de emergência, ou seja, de impacto imediato, e estritamente direcionada para os estudantes negros pela sua posição singular sador do Instituto de Pesquisa Econômica Aplicada (lpeal, diz que em 13 anos os brancos devem alcançar a média de oito anos de estudo. Os negros só atingirão essa meta daqui a 32 anos. Ou seja, só daqui a três décadas brancos e negros conseguirão concorrer em pé de igualdade a uma vaga no ensino superior público" (Weber, 2002, p. 6).

e vulnerável em todos os níveis escolares. Seus efeitos e repercussões esperam-se no curto e médio prazo, modificando já, e de forma muito concreta, os destinos de jovens que hoje se encontram cursando o segundo grau. De outra forma, suas inteligências e potencialidades, uma vez mais, poderiam perder-se para a vida intelectual da nação.
Não podemos permitir-nos, agora que pelas estatísticas sabemos, sacrificar mais uma geração, obrigando a nação a aguardar por mais $32 \operatorname{anos}^{2}$ para que possíveis melhoras na escola primária façam seu hipotético efeito na desigualdade racial.

\section{Eficácia experimental}

O sistema de cotas tem também a vantagem de permitir ser monitorado regularmente com o intuito de avaliar seu impacto na vida universitária em particular, no sistema educativo em geral e na sociedade como um todo. Constitui-se num verdadeiro laboratório de experimentação sociológicae pedagógica, um campo de observação onde os resultados da intervenção podem ser periodicamente verificados e submetidos à crítica. Os detalhes da intervenção, portanto, poderão ser corrigidos periodicamente porque o sistema de cotas implementado manterá seu caráter experimental. Ele permanecerá sujeito a modificações para aperfeiçoar o seu funcionamento, podendo sofrer ampliações ou reduções e, finalmente, vir a encerrar-se depois de a avaliação mostrar que as condições estão dadas para um progresso constante e irreversível da situação do negro na sala de aula e nos quadros profissionais.

Comoexperimento, ele foi acolhido sem esforço pela Universidade de Brasília, com cujo projeto de criação mantém afinidades incontestáveis. No programa de cotas, encontra eco o seu mandato de tornar-se instituição inovadora no campo da educação superior ensaiando sempre novos rumos para a expansão da inteligência brasileira. A partir do centro geográfico e político da nação, o projeto das vagas universitárias para negros vem irradiando sem dúvida sua influência benéfica pelo país afora.

\section{Eficácia pedagógica}

Os expertos na área de educação são unânimes hoje em afirmar que, em todos os níveis do sistema educativo, uma sala 
de aula onde convivem alunos de diversas origens étnicas, raciais, regionais, nacionais ou outras é mais apta para o aprendizado. Nela, a convivência plural e a constatação diária da diversidade própria do mundo cumprem um papel importante na formação profissional pois oferecem uma experiência mais rica e permitem acesso a uma realidade mais complexa. No Brasil, uma sala efetivamente mista do ponto de vista racial será, necessariamente, uma sala onde uma variedade de experiências e perspectivas irá conviver, uma lição diária de comunicação que ultrapassa as barreiras sociais; um treino em sociabilidade, adaptação e tolerância para todos, negros e brancos.

\section{Eficácia educativa de espectro}

\section{ampliado}

A medida terá repercussões importantes nos ensinos fundamental e médio:

- Crianças e adolescentes negros poderão encontrar estímulo vendo que adultos da sua cor são seus professores. Com isso, retroalimenta-se positivamente a pirâmide educativa, estimulando a confiança do aluno negro em suas possibilidades de realização futura.

- A exemplo do que ocorreu com a implantação do Programa de Avaliação Seriada (PAS), a medida estimula os estudantes negros no segundo grau da educação pública a demandar da escola e de seus professores um melhor nível de ensino para melhorar suas chances de performance e aproveitar a cota.

- Também seguindo o exemplo do PAS, a medida desafia os professores a empenharse em melhorar a performance específica dos seus alunos negros na avaliação. Ficarão estimulados, portanto, a acolher com maior interesse as demandas destes, já que a sociedade e a universidade voltaram sua atenção para o desempenho deles no processo de seleção.

Como conseqüência da discriminação negativa sofrida de forma permanente e naturalizada na sociedade brasileira fazem parte desse tipo deliberado de discriminação benigna e legítima.

\section{Eficácia política}

A implantação de um sistema de cotas tem, ainda, um efeito secundário, porém de extraordinária relevância: nele, a nação aceita publicamente sua responsabilidade pela prática sistemática do racismo ao longo da sua história-indicada já nos textos de todas as constituições brasileiras, sem exceção ${ }^{3}$. Acata, dessa forma, a denúncia da existência da discriminação racial na sociedade brasileira e aceita a dívida histórica para com seu componente negro. Esse processo de aceitação de responsabilidade, tema absolutamente atual da filosofia contemporânea ${ }^{4}$, é o único capaz de levar uma sociedade nacional à reconciliação e à paz.

As cotas agem, portanto, indiretamente, sinalizando a questão racial. Ao interpelar a sociedade, convocando-a a discutir o tema, o tornam visível para aqueles que nunca o enxergaram como problema porque nunca sentiram "na pele" os seus efeitos, ao mesmo tempo que dá oportunidade a suas vítimas para expor sua queixa. $\mathrm{Na}$ reação apaixonada que provocam, na forma um tanto excessiva ou até despropositada em que comovem e mobilizam os públicos, as cotas apontam para conteúdos insuspeitos que se abrigam nas profundezas de um psiquismo historicamente formado, deixam explícito o inominável. Elas instam a sociedade a refletir o irrefletido e a debater suas conseqüências.

Por tudo isso, as cotas são uma medida demonstrativa, que conduz os membros da comunidade universitária e a população em geral a tomar consciência do que é ser negro no Brasil.

\section{Eficácia formadora de cidadania}

As cotas são uma pedagogia cidadã porque a sua implantação revela à sociedade o seu poder de intervir e interferir ativamente no curso da história. Ao executar de forma
3 Cf. mostra o exmo. sr. ministro Marco Aurélio Mendes de Farias Mello, presidente do Supremo Tribunal Federal na sua palestra "Óptica Constitucional: a lgualdade e as Ações Afirmativas", proferida em 20 de novembro de 2001 no seminário sobre a Discriminação e Sistema Legal Brasileiro, promovido pelo Tribunal Superior do Trabalho.

4 Jacques Derrida (200 1), Paul Ricoeur (2000) e Günther Anders (2001) estão entre os grandes nomes da filosofia contemporânea que hoje trabalham sobre - tema da responsabilidade do perdão e da reconciliação possivel. 
deliberada uma ação de retificação histórica, a sociedade exibe e constata que tem liberdade e capacidade para escolher rumos novos, que é ela quem escreve a história. $\mathrm{O}$ membro de um conselho universitário que delibera e opta racionalmente por alterar a proporção de estudantes negros no seu estabelecimento no transcurso de um único ano assume a dimensão de um ator social poderoso, capaz de reverter, com um gesto simples, processos ancestrais injustos. Nesse sentido, a intervenção planejada em relação ao negro é somente emblemática de outras intervenções possíveis, e demonstra o poder que um grupo de cidadãos tem, em um determinado momento da história, de inventar e experimentar novas formas de convivência.

\section{Eficácia comunicativa}

Acor da pele negra é um signo ausente do texto visual geralmente associado ao poder, à autoridade e ao prestígio. A introdução desse signo modificará gradualmente a forma como olhamos e lemos a paisagem humana nos ambientes em que transitamos.

À medida que o signo do negro, o rosto negro, se fizer presente na vida universitária, assim como em posições sociais e profissões de prestígio em que antes não se inseria, essa presença tornar-se-á habitual e modificará as expectativas da sociedade. A nossa recepção do negro habilitado para exercer profissões de responsabilidade será automática e sem sobressaltos. O nosso olhar se fará mais democrático, mais justo. Não mais pensaremos que o médico negro é um servente do hospital. Nunca mais uma funcionária da Varig falará em inglês a um Milton Santos, na certeza de que, por seu porte digno, não poderia ser um negro brasileiro.

Um claro antecedente de que isso é possível é o ingresso da mulher, em décadas recentes, no exercício de profissões em que a sua presença não era habitual. Todos somos testemunhas de que a mulher médica, engenheira, executiva, gerente, chefe, deixou de ser um dado estranho à nossa percepção. E isso não aconteceu de forma espontânea, aconteceu devido à persistência e insistência dos movimentos de mulheres ao longo doúltimo século. Da mesma forma que aconteceu com as mulheres, ao inscrever o signo da negritude em todos os espaços e ambientes sociais, estaremos habituando - muito rapidamente - o olho coletivo a uma realidade mais humana. Entenderemos, por fim, que a cidadania deve e pode ser um bem universal.

\section{Eficácia propriamente transformadora}

Se a forma na qual apreendemos a estrutura hierárquica que organiza a realidade social é a partir de sua fixação nos signos em que se representa, e se esses signos são, também, a caução de sua reprodução, ao decretar a mobilidade desses signos é possível que alcancemos a estrutura em alguns dos seus pontos de vulnerabilidade e lhe causemos dano. Pode-se pensar que, ao chacoalhar os signos, acabemos por minar, erosionar, desestabilizar a estrutura no seu lentíssimo ritmo de reprodução histórica. Porém, introduzir o signo da pessoa negra em certos cenários onde ele não circulava não basta. É necessário fazê-lo reflexivamente, deliberativamente.

Não basta essa circulação do signo negro por posições não habituais - pois ela, de fato, sempre aconteceu como exceção, na história. É necessária sua formulação em conceitos e categorias que inscrevam esse movimento nas narrativas mestras do sistema - a lei, a moral, o costume. Eu diria que tornar híbridas as posições da estrutura ferrenhamente hierárquicas é uma má prática dos papéis sociais, que pode acabar por levar à obsolescência a prescrição estrutural. Penso que a má prática da estrutura e o jogo sígnico podem inocular no senso comum uma importante dúvida sobre a a-historicidade naturalizada da estrutura, e esta dúvida pode levá-la a caducar, a desmontar-se lentamente na sua eficácia e nos sistemas de autoridade que sustenta. Poderia 
vislumbrar-se assim a possibilidade da desprogramação do sistema.

Um caso inverso ao que descrevo é, por exemplo, o de Cuba, onde se movimentou a estrutura econômica mas não se tocou na posição dos signos raciais, que acabaram fazendo seu papel de retenção e proteção da inércia e persistência do sistema. As pessoas são unânimes em dizer que, apesar da intensa democratização da educação, com a instalação da economia dupla depois do período especial, o abismo racial voltou a instalar-se e aumentou, seja porque os emigrados, transformados em fonte de divisas para suas famílias, são brancos e, portanto, seus aportes enriquecem as famílias brancas que ficaram em Cuba, seja porque os em- pregos mais bem remunerados nas novas empresas que se instalaram na ilha com a abertura da economia foram para pessoas brancas. Isso mostra que a movimentação dos signos é, nos processos inclusivos e redistributivos, tanto ou mais importante que a introdução de novas regras para o sistema econômico.

O jogo dos signos é, por enquanto, tudo o que temos: anarquizar com uma performance defeituosa a vitrine em que o sistema se apresenta. Nessa proposta, os meios são mais importantes do que os fins (em lugar de os fins tornarem irrelevantes os meios, no estilo do período setentista), porque os meios são a única coisa que temos como possibilidade prática e a única certeza.

\section{BIBLIOGRAFIA}

ANDERS, Günther. Nosotros, los Hijos de Eichmann. Carta Abierta a Klaus Eichmann. Barcelona e Buenos Aires, Paidós, 2001 (1988).

CARVALHO, José Jorge \& SEGATO, Rita Laura. Uma Proposta de Cotas para Estudantes Negros na Universidade de Brasília. Série Antropologia 314. Brasília, Departamento de Antropologia, Universidade de Brasília, 2002.

DERRIDA, Jacques: "Justicia y Perdón", in Palabra! Instantaneas Filosóficas. Madrid, Trotta, 2001.

MEDEIROS, Marcelo. "Composição Racial das Famílias no Brasil", Seminário Interno da Coordenação de População e Família, Instituto de Pesquisa Econômica Aplicada (Ipea), janeiro de 2002, mimeo.

MELLO, Marco Aurélio Mendes de Farias. "Óptica Constitucional: a Igualdade e as Ações Afirmativas", palestra de abertura do seminário sobre Discriminação e Sistema Legal Brasileiro. Tribunal Superior do Trabalho, 20 de novembro de 2001.

RICOEUR, Paul. La Mémoire, L'Histoire, L'Oublie. Paris, Editions du Seuil, 2000.

SYMONIDES, Janusz \& VOLODIN, Vladimir (eds.). A Guide to Human Rights. Institutions, Standards, Procedures. Paris, Unesco, 2001.

VALLE SILVA, Nelson do. "Distância Social e Casamento Inter-racial no Brasil”, in Nelson do Valle Silva e Carlos A. Hasenbalg (eds.). Relações Raciais no Brasil Contemporâneo. Rio de Janeiro, Rio Fundo, 1992.

WEBER, Luiz Alberto. "Combate ao Racismo", in Correio Braziliense. Brasília, 27 de fevereiro de 2002, p. 6. 